\title{
Magnitude determination using duration of high frequency energy radiation and displacement amplitude: application to tsunami earthquakes
}

\author{
Tatsuhiko Hara \\ International Institute of Seismology and Earthquake Engineering, Building Research Institute, 1 Tatehara, Tsukuba, Ibaraki 305-0802, Japan
}

(Received December 9, 2006; Revised March 31, 2007; Accepted April 13, 2007; Online published June 27, 2007)

\begin{abstract}
Recently, we developed a new method to determine earthquake magnitudes using durations of high frequency energy radiation and the maximum displacement amplitudes, which can be measured from processing of first arriving $P$-waves. In the present study, we applied this method to the 1992 Nicaragua, 1994 Java, 1996 Peru, and 2006 Java earthquakes which have been suggested to be "tsunami earthquakes." Our magnitude estimates for these earthquakes are consistent with the moment magnitudes in the Global CMT catalog, which demonstrates that our method is applicable to tsunami earthquakes. The analyzed tsunami earthquakes are characterized in our method as those with longer source durations and smaller displacement amplitudes.
\end{abstract}

Key words: Magnitude, tsunami earthquake, high frequency energy radiation.

\section{Introduction}

Rapid magnitude determination is essential for tsunami warnings. The recent two large tsunamigenic earthquakes, the December 26, 2004 Sumatra $\left(M_{w} 9.0\right)$ and the July 17, 2006 Java $\left(M_{w}\right.$ 7.7) earthquakes, have shown that rapid magnitude determination still needs further improvements. For the case of the 2004 Sumatra earthquake, it took more than four hours to obtain an estimate of $M_{w} 8.9$ (Park et al., 2005a). This stimulated many seismologists to develop new methods for rapid magnitude determination for huge earthquakes such as the Sumatra earthquake (Menke and Levin, 2005; Lomax, 2005; Lomax and Michelini, 2005; Park et al., 2005b; Ni et al., 2005; Bormann and Wylegalla, 2005). For the case of the 2006 Java earthquake, USGS issued $M_{s}$ 7.2 and $M_{w}$ 7.2, and PTWC (Pacific Tsunami Warning Center) estimated an $M_{w p}$ (Tsuboi et al., 1995, 1999) of 7.2 , and $M_{w} 7.4$ (calculated from $M_{m}$ (Okal and Talandier, 1989) following Weinstein and Okal (2005)), while the Global CMT project (formerly known as the Harvard CMT project, and currently available at http://www.globalcmt.org/) provided $M_{w}$ 7.7. Several studies analyzing seismic waves (Ammon et al., 2006; Yagi, 2006; Ji, 2006) and tsunamis (Fujii and Satake, 2006) suggested that $M_{w}$ of this earthquake is around or greater than 7.7. This case illustrates that the current routine magnitude determination may fail for such earthquakes as the 2006 Java earthquake. This can be a serious problem for tsunami warnings.

Recently, we developed a new method of magnitude determination (Hara, 2007). In this method, magnitudes are determined using durations of high frequency energy radiation and the maximum displacement amplitudes measured from first arriving $P$-waves recorded at tele-seismic

Copyright (c) The Society of Geomagnetism and Earth, Planetary and Space Sciences (SGEPSS); The Seismological Society of Japan; The Volcanological Society of Japan; The Geodetic Society of Japan; The Japanese Society for Planetary Sciences; TERRAPUB. distance range. We showed that this method was applicable to shallow large $\left(M_{w} \geq 7.2\right)$ earthquakes including the 2004 Sumatra earthquake, and that this method would be effective for rapid magnitude determination for tele-seismic events.

In the present study, we investigated the applicability of this method to "tsunami earthquakes" (Kanamori, 1972). We chose the 1992 Nicaragua, 1994 Java, 1996 Peru, and 2006 Java earthquakes in this study. $M_{w}$ and $M_{s}$ for these events are shown in Table 1 together with their origin times and hypocenters. $M_{w}$ is significantly larger than $M_{s}$ for these earthquakes, which is a characteristic of tsunami earthquakes. Many studies have suggested that these events are tsunami earthquakes (e.g., Kanamori and Kikuchi, 1993; Newman and Okal, 1998; Polet and Kanamori, 2000). We show $M_{t}$ (tsunami magnitude. Abe, 1979, 1981) in Table 1 if available.

\section{Analyses}

We retrieved BHZ channel waveform data recorded at the Global Seismograph Network (GSN) stations from IRIS DMC. Following Ni et al. (2005), we analyzed data from stations in the epicentral distance range of 30-85 degrees to avoid scattering due to the upper mantle or $\mathrm{D}^{\prime \prime}$ structures (Shearer and Earle, 2004). Although the difference between $P$ and $S$ arrival times is about $300 \mathrm{~s}$ at 30 degree, it is likely to be possible to measure longer source duration, since, as was suggested by Ni et al. (2005), later phases such as $P P$ and $S$ are suppressed within $2-4 \mathrm{~Hz}$ band. We also used data from FDSN stations in the same epicentral distance range for the 1992 Nicaragua and 1996 Peru earthquakes, since the numbers of available stations are small. The number of the stations used for each earthquake is shown in Table 2.

We followed the data processing procedure of Hara (2007). First, we determine duration of high frequency energy radiation through band-pass filtering (corner frequencies are 2 and $4 \mathrm{~Hz}$ ), calculation of squares, and applying 
Table 1. The origin times, hypocenters, and magnitudes of the events analyzed in this study.

\begin{tabular}{lccccc}
\hline Event & Origin time (UT) & Hypocenter (lat, lon, and depth) & $M_{w}$ & $M_{t}$ & $M_{s}$ \\
\hline 1992 Nicaragua & SEP 02, 00:16:01.6 & $11.742 \mathrm{~N} ; 87.340 \mathrm{~W} ; 45 \mathrm{~km}$ & 7.6 & $8.0^{(1)}$ & 7.2 \\
1994 Java & JUN 02, 18:17:34.0 & $10.477 \mathrm{~S} ; 112.835 \mathrm{E} ; 18 \mathrm{~km}$ & 7.8 & - & 7.2 \\
1996 Peru & FEB 21, 12:51:01.3 & $9.593 \mathrm{~S} ; 79.587 \mathrm{~W} ; 10 \mathrm{~km}$ & 7.5 & $7.8^{(2)}$ & 6.6 \\
2006 Java & JUL 17, 08 1928.7 & $9.254 \mathrm{~S} ; 107.411 \mathrm{E} ; 34 \mathrm{~km}$ & 7.7 & - & 7.2 \\
\hline
\end{tabular}

The origin times, hypocenters, and $M_{s}$ are from the USGS bulletins. $M_{w}$ is from the Global CMT catalog. (1) Ide et al. (1993); (2) Abe (1996).
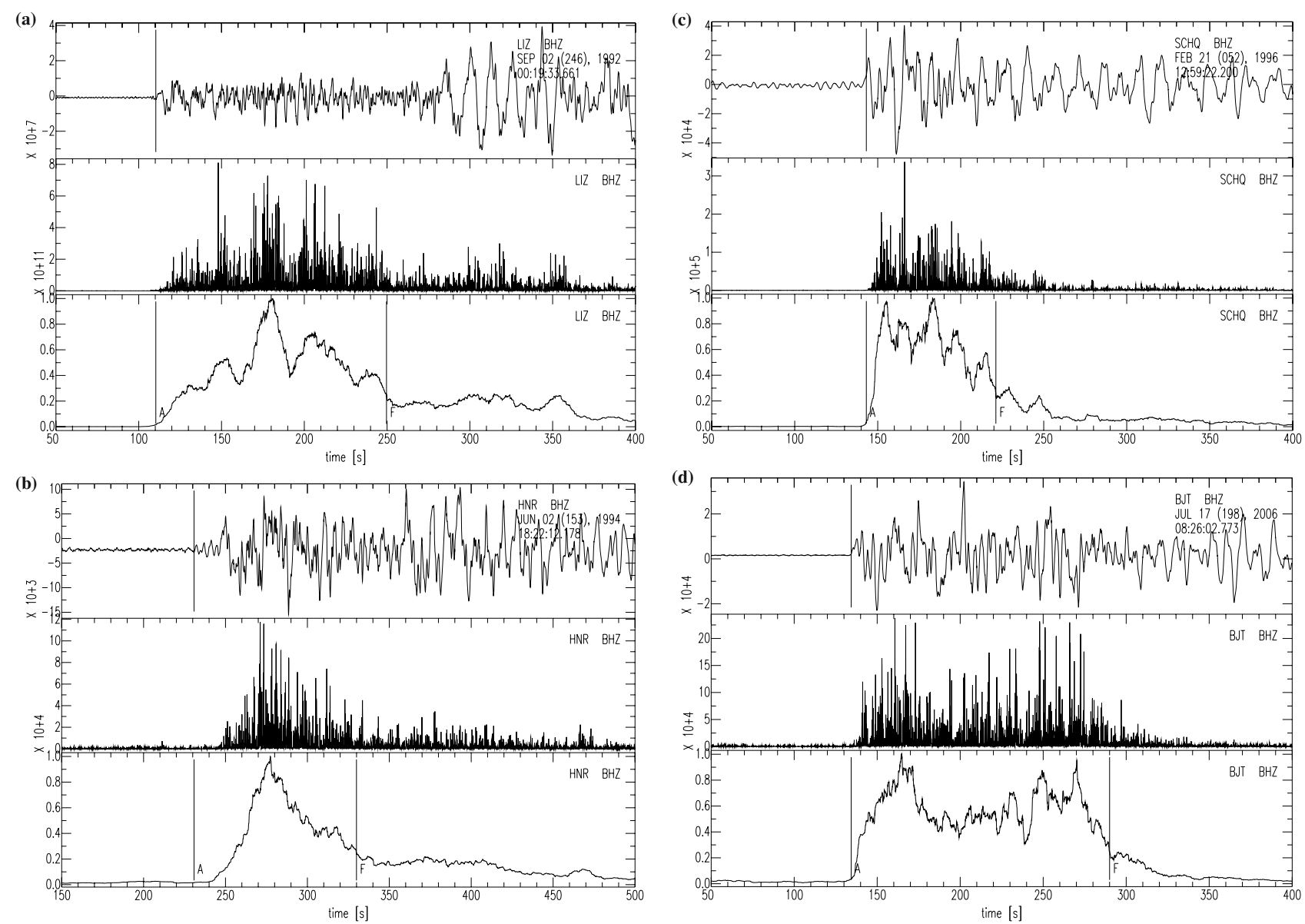

Fig. 1. Examples of measurements of high frequency energy radiation for the September 2, 1992 Nicaragua (a), the June 2, 1994 Java (b), the February 21, 1996 Peru (c), and the July 17, 2006 Java (d) earthquakes. The epicentral distances are 31.5, 46.4, 65.1 and 49.8 degrees, respectively. The top, middle and bottom traces in (a)-(d) are an observed seismogram, a time series of squares of band-pass (2-4 Hz) filtered seismogram, and its smoothed time series (normalized by the maximum value), respectively. "A" and "F" in the bottom traces denote arrivals of $P$-waves and estimated ends of high frequency energy radiation, respectively.

moving window average for smoothing. As the end time of high-frequency energy radiation, we chose the time when the amplitude of the smoothed time series became smaller than 25 per cent of its maximum value. The details are described in Hara (2007). Figure 1 shows examples of duration measurements, and Table 2 shows the obtained estimates. As an estimate for each earthquake, we chose the median among estimates obtained for all of stations. In Table 2, we also show the doubled time differences between the origin and centroid times in the Global CMT catalog, which can be used as estimates of source durations. Our duration estimates are consistent with long source durations inferred from the Global CMT solutions, although our estimates are several tens per cent larger. Our estimates are more consistent with source durations determined by de- tailed source process studies (Table 2). This suggests that the duration measurement procedure of Hara (2007) is applicable to estimation of source durations of tsunami earthquakes.

Then, we determined earthquake magnitudes using the following formula (Hara, 2007):

$$
M=0.79 \log A+0.83 \log \Delta+0.69 \log t+6.47
$$

where $M$ is an earthquake magnitude, $A$ is the maximum displacement $(\mathrm{m})$ during the estimated duration of highfrequency energy radiation from the arrival time of a $P$ wave, $\Delta$ is the epicentral distance $(\mathrm{km}), t$ is the estimated duration (s) of high-frequency energy radiation. In the case where a direct $S$ wave was expected to arrive within the estimated duration, we used a time series from the arrival 
Table 2. The measured durations of high frequency energy radiation and source time estimates.

\begin{tabular}{lcccc}
\hline Event & Duration $(\mathrm{s})$ & (C.T.-O.T.) $\times 2(\mathrm{~s})$ & Source time estimates (s) & No. of stations \\
\hline 1992 Nicaragua & 139.4 & 89 & $100-110^{(1)}$ & 11 \\
1994 Java & 96.5 & 78 & $80-90^{(2)}$ & 18 \\
1996 Peru & 78.1 & 45.4 & $50-60^{(3)}$ & 23 \\
2006 Java & 155.6 & 138.2 & $\geq 150^{(4)}$ & 26 \\
\hline
\end{tabular}

"Duration (s)" is the estimate of duration of high frequency energy radiation. "(C.T.-O.T.) $\times 2$ " is the doubled difference between centroid time in the Global CMT catalog and origin time in the USGS bulletin. "Source time estimates (s)" shows a source time estimate from previous studies. Their references are as follows. (1) Ide et al. (1993), Kanamori and Kikuchi (1993), Kikuchi and Kanamori (1995), Velasco et al. (1994), Ihmlé (1996); (2) Abercrombie et al. (2001); (3) Ihmlé et al. (1998), Bourgeois et al. (1999); (4) Ammon et al. (2006), Ji (2006), Yagi (2006). "No. of stations" is the number of stations used in this study.

Table 3. The magnitude estimates obtained in this study and those of $M_{w p}, M_{w}\left(M_{m}\right)$, and $M_{w}$.

\begin{tabular}{ccccc}
\hline Event & M (this study) & $M_{w p}$ & $M_{w}\left(M_{m}\right)$ & $M_{w}$ \\
\hline 1992 Nicaragua & 7.52 & $7.2^{(1)}$ & $7.55^{(2)}$ & 7.6 \\
1994 Java & 7.78 & $7.5^{(1)}$ & $7.65^{(2)}$ & 7.8 \\
1996 Peru & 7.35 & $7.5^{(1)}$ & $7.45^{(2)}$ & 7.5 \\
2006 Java & 7.66 & 7.2 & 7.4 & 7.7 \\
\hline
\end{tabular}

(1) Tsuboi (2000). (2) $M_{w}\left(M_{m}\right)$ was introduce by Weinstein and Okal (2005). We calculated this scale using the averages of the $M_{m}$ estimates presented by Newman and Okal (1998). $M_{w p}$ and $M_{w}\left(M_{m}\right)$ for the 2006 Java earthquake are from PTWC. $M_{w}$ is from the Global CMT catalog (although they are shown in Table 1, we show them here again for comparison).

time of a $P$ wave to the theoretical arrival time of a $S$ wave computed for iasp91 (Kennett and Engdahl, 1991). As an estimate for each earthquake, we chose the median among estimates obtained for all of stations. We show the magnitude estimates in Table 3. These estimates agree well with $M_{w}$ in the Global CMT catalog, which suggests that the magnitude determination of Hara (2007) is applicable to tsunami earthquakes. Among the four earthquakes, the 1996 Peru earthquake was included in 69 earthquakes that Hara (2007) analyzed to construct Eq. (1). The estimated duration of high frequency energy radiation and magnitude using data from 13 GSN stations was $61.3 \mathrm{~s}$ and 7.15, respectively. We added data from 10 FDSN stations, and then obtained 78.1 s and 7.35, respectively, in this study. This case implies that data from around or more than 20 stations should be necessary to obtain a reliable estimate.

\section{Discussion}

We showed above that it was possible to determine magnitudes of tsunami earthquakes consistent with $M_{w}$ in the Global CMT catalog following the procedure of Hara (2007). As is shown in Table $1, M_{t}$ is larger than $M_{w}$ for the 1992 Nicaragua and 1996 Peru earthquakes, and the magnitude estimates obtained in this study are underestimates for $M_{t}$. However, since our estimates are significantly larger than $M_{s}$, and close to $M_{w}$, our method will be useful for tsunami warnings for tele-seismic events.

PTWC determines $M_{w p}$ and $M_{w}\left(M_{m}\right)$ (Weinstein and Okal, 2005) for tsunami warnings. Table 3 shows the estimates of these magnitude scales for the earthquakes analyzed in this study. Our estimates better agree with $M_{w}$ in the Global CMT catalog generally, while $M_{w p}$ and $M_{w}$ $\left(M_{m}\right)$ better agrees for the 1996 Peru earthquake. How to utilize these measurements for tsunami warning is important subject and should be carefully investigated.

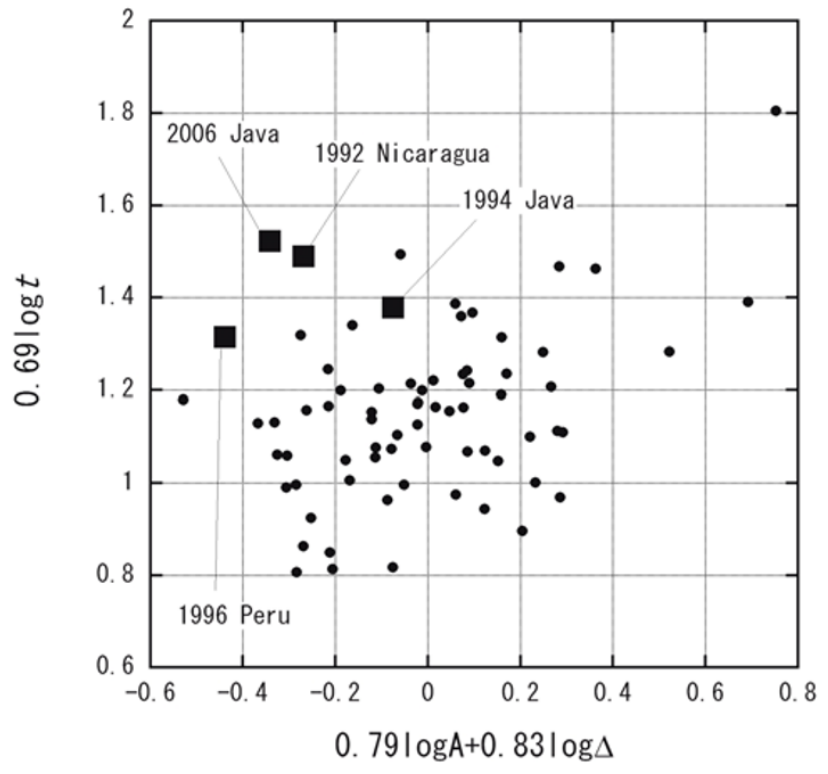

Fig. 2. Contributions to magnitudes from maximum displacement amplitudes and epicentral distances (the horizontal axis) and those from durations of high frequency energy radiation (the vertical axis) are plotted for the earthquakes analyzed in this study and those analyzed by Hara (2007) as squares and dots, respectively.

The magnitude determined by Eq. (1) has two contributions: one from the maximum displacement amplitude (with correction for epicentral distance), and the other from duration of high frequency energy radiation. Figure 2 shows these two contributions for the earthquakes analyzed in this study and those that Hara (2007) analyzed (for the 1996 Peru earthquake, we show the result of this study, because, as was mentioned in the previous section, the result obtained by Hara (2007) using data from fewer stations is 
less reliable). The tsunami earthquakes are characterized as those for which contributions from the maximum displacement amplitudes are relatively smaller, and those from durations are relatively larger. Therefore, quick identification of tsunami earthquakes may be possible through analyses of first arriving $P$-waves using our method.

Newman and Okal (1998) calculated radiated seismic energy using broadband records at tele-seismic distances. They analyzed the ratio of seismic energy to seismic moment, which they defined as $\Theta$, and showed that tsunami earthquakes were characterized by deficiency of this parameter. They proposed application of their energy computation formalism coupled with $M_{m}$ measurements for tsunami warning. Weinstein and Okal (2005) reported the results of routine measurements of $M_{m}$ and $\Theta$ at the Pacific Tsunami Warning Center. Since only the duration of high frequency energy radiation is taken into account in our method, it will be interesting to combine our method and radiated seismic energy to improve the characterization of earthquakes.

Recently, there have been done several studies to utilize high frequency energy radiation for quantification of earthquake sizes. Chen et al. (2006) obtained high frequency source time function of the July 17, 2006 Java earthquake by deconvolution using waveforms from aftershocks as empirical Green's function. Lomax et al. (2006) derived the expression of energy-duration magnitude based on the Haskell model with measurements of radiated seismic energy and source duration. They showed that their magnitude estimates (including those for the December 26, 2004 Sumatra earthquake and the tsunami earthquakes analyzed in this study) were consistent with $M_{w}$ of the Global CMT catalog.

The results of Hara (2007), Lomax et al. (2006) and the present study suggest that utilization of high frequency energy radiation is promising approach for rapid magnitude determination. These methods are similar in that duration of high frequency energy radiation is taken into account. While the expression of Lomax et al . (2006) is derived theoretically based on the Haskell model, Hara (2007) adopted an empirical relation between magnitudes and observables (i.e., durations of high frequency energy radiation, the maximum displacement amplitudes, and epicentral distances). In terms of the length of time series required for processing, a time series from $P$ arrival up to the end of high frequency energy radiation is necessary in the method of Hara (2007), while a time series from 10 seconds before $P$ arrival to 10 seconds before $S$ arrival is used by Lomax et al. (2006). Therefore, potentially, the method of Hara (2007) can determine magnitudes more rapidly. However, it is early to rigorously compare results from these methods, because both of them will be subject to further improvements in their algorithms and implementations.

Acknowledgments. The author thanks for Hiroo Kanamori for his comments on this study. The author is grateful for Tetsuzo Seno and Yushiro Fujii for sending me their preprints of their studies on tsunami earthquakes. The author thanks for Katsuyuki Abe and Barry Hirshorn for providing me with information on their magnitude estimates. The author also thanks the anonymous referees for their comments on the earlier version of this paper, which are effective to improve the manuscript.

\section{References}

Abe, K., Size of great earthquakes of 1837-1974 inferred from tsunami data, J. Geophys. Res., 84, 1561-1568, 1979.

Abe, K., Physical size of tsunamigenic earthquakes of the northwestern Pacific, Phys. Earth Planet. Inter., 27, 194-205, 1981.

Abe, K., Tsunami Magnitude of the 21 February 1996 Peru event; E-mail communication via the tsunami bulletin board, 1996.

Abercrombie, R. E., M. Antolik, K. Felzer, and G. Ekström, The 1994 Java tsunami earthquake: Slip over a subducting seamount, J. Geophys. Res., 106, 6595-6608, 2001.

Ammon, C. J., H. Kanamori, T. Lay, and A. A. Velasco, The 17 July 2006 Java Tsunami Earthquake, Geophys. Res. Lett., 33, L24308, doi:10. 1029/2006GL028005, 2006.

Bormann, P. and K. Wylegalla, Quick Estimator of the Size of Great Earthquakes, Eos Trans. AGU, 86(46), 464, 2005.

Bourgeois J., C. Petroff, H. Yeh, V. Titov, C. E. Synolakis, B. Benson, J Kuroiwa, J. Lander, and E. Norabuena, Geologic Setting, Field Survey and Modeling of the Chimbote, Northern Peru, Tsunami of 21 February 1996, Pure Appl. Geophys., 154, 513-540, 1999.

Chen, Y., J. Huang, S. Ni, and Y. Chen, Slow rupture velocity of the July 17th, 2006 Java earthquake from high frequency analysis, Eos Trans. $A G U$, 87(52), Fall Meet. Suppl., Abstract S21A-0128, 2006.

Fujii Y. and K. Satake, Source of the July 2006 West Java Tsunami Estimated from Tide Gauge Records, Geophys. Res. Lett., 33, L24317, doi:10.1029/2006GL028049, 2006.

Hara, T., Measurement of duration of high-frequency energy radiation and its application to determination of magnitudes of large shallow earthquakes, Earth Planets Space, 59, 227-231, 2007.

Ide, S., F. Imamura, Y. Yoshida, and K. Abe, Source characteristics of the Nicaraguan tsunami earthquake of September 2, 1992, Geophys. Res. Lett., 20, 863-866, 1993.

Ihmlé, P. F., Monte Carlo slip inversion in the frequency domain: Application to the 1992 Nicaragua slow earthquake, Geophys. Res. Lett., 23, 913-916, 1996.

Ihmlé, P. F., J.-M. Gomez, P. Heinrich, and S. Guibourg, The 1996 Peru tsunamigenic earthquake: broadband source process, Geophys. Res. Lett., 25, 2691-2694, 1998.

Ji, C., http://neic.usgs.gov/neis/eq_depot/2006/eq_060717_qgaf/neic_qgaf_ ff.html, 2006.

Kanamori, H., Mechanism of tsunami earthquakes, Phys. Earth Planet. Inter., 6, 346-359, 1972.

Kanamori, H. and M. Kikuchi, The 1992 Nicaragua earthquake: a slow tsunami earthquake associated with subducted sediments, Nature, 361, 714-716, 1993.

Kennett, B. L. N. and E. R. Engdahl, Traveltimes for Global Earthquake Location and Phase Identification, Geophys. J. Int., 105, 429-465, 1991.

Kikuchi, M. and H. Kanamori, Source characteristics of the 1992 Nicaragua tsunami earthquake inferred from teleseismic body waves, Pure Appl. Geophys., 144, 441-453, 1995.

Lomax, A., Rapid estimation of rupture extent for large earthquakes: Application to the 2004, M9 Sumatra-Andaman mega-thrust, Geophys. Res. Lett., 32, L10314, doi:10.1029/2005GL022437, 2005.

Lomax, A. and A. Michelini, Rapid determination of earthquake size for hazard warning, Eos Trans. AGU, 86(21), 202, 2005.

Lomax, A., A. Michelini, and A. Piatanesi, An Energy-Duration Procedure for Rapid, Robust and Accurate Determination of Earthquake Magnitude and Tsunamigenic Potential: Application to the 26 December 2004, Sumatra-Andaman, 17 July 2006, Java and other large earthquakes, Eos Trans. AGU, 87(52), Fall Meet. Suppl., Abstract S21A-0131, 2006.

Menke, W. and V. Levin, A strategy to rapidly determine the magnitude of great earthquakes, Eos Trans. AGU, 86(19), 185, 2005.

Newman A. V. and E. A. Okal, Teleseismic estimates of radiated seismic energy: The E/ $M_{0}$ discriminant for tsunami earthquakes, J. Geophys. Res., 103, 26885-26898, 1998.

Ni, S., H. Kanamori, and D. Helmberger, Energy radiation from the Sumatra earthquake, Nature, 434, 582, 2005.

Okal, E. A. and J. Talandier, $M_{m}$ : A variable-period mantle magnitude, $J$. Geophys. Res., 94, 4169-4193, 1989.

Park, J., R. Butler, K. Anderson, J. Berger, H. Benz, P. Davis, C. R. Hutt, C. S. McCreery, T. Ahern, G. Ekström, and R. Aster, Performance review of the global seismographic network for the Sumatra-Andaman megathrust earthquake, Seism. Res. Lett., 76, 331-343, 2005a.

Park, J., K. Anderson, R. Aster, R. Butler, T. Lay, and D. Simpson, Global seismographic network records the great Sumatra-Andaman earthquake, Eos Trans. AGU, 86(6), 57, 2005b. 
Polet J. and H. Kanamori, Shallow subduction zone earthquakes and their tsunamigenic potential, Geophys. J. Int., 142, 684-702, 2000.

Shearer, P. M. and P. S. Earle, The global short-period wavefield modelled with a Monte Carlo seismic phonon method, Geophys. J. Int., 158, 1103-1117, 2004.

Tsuboi, S., Application of Mwp to tsunami earthquake, Geophys. Res. Lett., 27, 3105-3108, 2000.

Tsuboi, S., K. Abe, K. Takano, and Y. Yamanaka, Rapid Determination of Mw from Broadband P Waveforms, Bull. Seism. Soc. Am., 85, 606-613, 1995.

Tsuboi, S., P. M. Whitmore, and T. J. Sokolowski, Application of Mwp to Deep and Teleseismic Earthquakes, Bull. Seism. Soc. Am., 89, 13451351, 1999.
Velasco, A. A., C. J. Ammon, T. Lay, and J. Zhang, Imaging a slow bilateral rupture with broadband seismic waves: The September 2, 1992 Nicaraguan tsunami earthquake, Geophys. Res. Lett., 21, 2629-2632, 1994.

Weinstein, S. A. and E. A. Okal, The Mantle Magnitude $M_{m}$ and the Slowness Parameter $\Theta$ : Five Years of Real-Time Use in the Context of Tsunami Warning, Bull. Seism. Soc. Am., 95, 779-799, 2005.

Yagi, Y., http://www.geo.tsukuba.ac.jp/press_HP/yagi/EQ/20060717Jawa/ index.html, 2006.

T. Hara (e-mail: thara@kenken.go.jp) 